\title{
The Measurement of Eye Contact in Human Interactions: A Scoping Review
}

\author{
Chiara Jongerius $^{1} \cdot$ Roy S. Hessels $s^{2,3}$. Johannes A. Romijn ${ }^{4} \cdot$ Ellen M. A. Smets $^{1}$. \\ Marij A. Hillen ${ }^{1}$
}

Published online: 20 April 2020

(C) The Author(s) 2020

\begin{abstract}
Eye contact is a fundamental aspect of nonverbal communication and therefore important for understanding human interaction. Eye contact has been the subject of research in many disciplines, including communication sciences, social psychology, and psychiatry, and a variety of techniques have been used to measure it. The choice of measurement method has consequences for research outcomes and their interpretation. To ensure that research findings align with study aims and populations, it is essential that methodological choices are well substantiated. Therefore, to enhance the effective examination of eye contact, we performed a literature review of the methods used to study eye contact. We searched Medline, PsycINFO and Web of Science for empirical peer-reviewed articles published in English that described quantitative studies on human eye contact and included a methodological description. The identified studies $(N=109)$ used two approaches to assess eye contact: direct, i.e., assessing eye contact while it is occurring, and indirect, i.e., assessing eye contact retrospectively (e.g., from video recordings). Within these categories, eight specific techniques were distinguished. Variation was found regarding the reciprocity of eye contact between two individuals, the involvement of an assessor and the behavior of participants while being studied. Measures not involving the interactors in assessment of eye contact and have a higher spatial and temporal resolution, such as eye tracking, have gained popularity. Our results show wide methodological diversity regarding the measurement of eye contact. Although studies often define eye contact as gaze towards an exact location, this may not do justice to the subjective character of eye contact. The various methodologies have hardly ever been compared, limiting the ability to compare findings between studies. Future studies should take notice of the controversy surrounding eye contact measures.
\end{abstract}

Chiara Jongerius

c.jongerius@amsterdamumc.nl

1 Department of Medical Psychology, Amsterdam Public Health Research Institute, Academic Medical Center, Amsterdam UMC, University of Amsterdam, Meibergdreef 9, 1100 DD Amsterdam, The Netherlands

2 Experimental Psychology, Helmholtz Institute, Utrecht University, Utrecht, The Netherlands

3 Developmental Psychology, Utrecht University, Utrecht, The Netherlands

4 Department of Medicine, Amsterdam UMC, University of Amsterdam, Amsterdam, The Netherlands 
Keywords Eye contact $\cdot$ Mutual gaze $\cdot$ Assessment $\cdot$ Measurement $\cdot$ Technique

\section{Introduction}

Eye contact is a fundamental aspect of nonverbal communication and social interaction from birth throughout adulthood (Kleinke 1986). Eye contact is an important indicator for healthy bonding between mother and child at early ages and for the diagnosis of psychiatric disorders later in life (Auyeung et al. 2015; Farroni et al. 2002). Furthermore, it is a fundamental factor in interpersonal relationship building (MacDonald 2009). Not surprisingly, eye contact has been the focus of research in various disciplines, such as communication sciences, social psychology, and psychiatry, and various approaches have been used to asses it.

Health communication research has, for example, focused on eye contact between patient and physician and on turn-taking in conversations. The focus of such research has been on the impact of eye contact on patients' levels of trust, anxiety, and satisfaction (Farber et al. 2015; Hillen et al. 2015; Pieterse et al. 2007). Within this line of research, researchers have used video cameras to observe the gaze behavior of patients and physicians (Farber et al. 2015; Pieterse et al. 2007). Clinical consultations were filmed and, subsequently, physicians' and patients' gaze behaviors were coded by researchers using software for behavioral coding (Farber et al. 2015; Pieterse et al. 2007). As regards turntaking, studies have observed people involved in a conversation and have, for example, related their amount of gaze to their proportion of speaking time to gain insight into the 'smoothness' of encounters (Kalma 1992; Kendon and Cook 1969). These studies have identified patterns of gaze in interactions indicating that someone is speaking, listening or inviting another interactor to take over.

In the field of social psychology, eye contact has, for example, been studied as a way for different individuals or groups to approach or deceive each other (Kleinke 1986). To understand how eye contact enables approaching behavior, eye contact is usually experimentally enhanced or obstructed during social encounters. Afterwards, effects are assessed on outcomes such as distance and affiliation (Argyle and Dean 1965; Knight et al. 1973). Studies focusing on deception and manipulation have compared the amount of eye contact between participants instructed to lie with a control group of truth-tellers (Jundi et al. 2013; Mann et al. 2013).

Research on eye contact within psychiatry often focuses on disturbed eye contact patterns as a potential indicator of psychiatric pathologies (Guillon et al. 2014; Papagiannopoulou et al. 2014; Schulze et al. 2013). Such studies have, for instance, found that individuals diagnosed with autism spectrum disorder tend to gaze less at the eye area compared to healthy individuals (Guillon et al. 2014; Papagiannopoulou et al. 2014; van der Geest et al. 2002). These studies generally use the amount of eye-directed gaze as a proxy for eye contact. For example, in a recent study, individuals diagnosed with autism spectrum disorder were instructed to look at the eye-region of faces in pictures. This allowed the researchers to examine the neurological effects of their gaze behavior in the subcortical system using fMRI (Hadjikhani et al. 2017). As illustrated, eye contact is central to research in various disciplines focused on understanding human interaction, using a variety of measurement strategies. As eye contact is such a crucial indicator of interpersonal relationships, clarity is needed about how it is defined. Moreover, valid and reliable methods should be chosen to assess it, appropriate for the specific 
research aim and population. If we want to aggregate and advance research on interpersonal eye contact, we need a clear overview of the different methodologies and their interpretations.

Several previous reviews have grouped the literature on eye contact. For example, the importance of eye contact in patient-physician communication was reviewed by MacDonald (2009). Furthermore, Senju and Johnson (2009a) reviewed the effect of (perceived) eye contact on cognitive processing. More recently, Grossmann (2017) reviewed eye contact from an ontogenetic, phylogenetic, neurological, and neuro-hormonal perspective. These reviews have proposed multiple interpretations and models for understanding eye contact. However, they did not take into account the methodological variations in empirical studies on eye contact. A methodological review may provide insight into the implicit assumptions made by researchers about what eye contact is.

Although many researchers state they aim to investigate "eye contact", variation in the methodologies to measure it complicates aggregation or comparison of study findings. Therefore, our aim was to provide an overview of the methods used to study eye contact across research disciplines. More specifically, we investigated how eye contact is defined and assessed in the empirical literature to uncover the specific techniques that have been used in eye contact research. To that end, we analyzed for individual studies general characteristics (study design, cohort, and field of study), operationalization of eye contact, and participant behavior under investigation. More generally, we analyzed the evolvement of eye contact measures over time, and the covariances between the operationalizations, age group of participants, field of study, and research question.

\section{Method}

\section{Search Strategy}

We conducted a bibliographic search in Medline, PsycINFO, and Web of Science, using the following terms: (eye contact) OR ((direct OR mutual OR dyadic OR eye) AND (gaze OR gazing)). For the exact search strings per database see "Appendix 1". The search terms were refined beforehand based on the scope of our research question, literature, an initial exploratory search, and consultation with expert librarians. The search was limited to journal articles written in the English language. The last search date was February 8,2018 . The review was registered in the PROSPERO database, registration number: CRD42018094107. One study not identified in the initial search was added based on expert opinion of one of the reviewers.

\section{Article Selection}

Once the search was completed, two authors (CJ, MH) independently screened and discussed 100 articles based on their title and abstract to refine the inclusion criteria. Using these criteria, the same two authors independently screened 500 titles and abstracts to assess congruence and to refine exclusion and inclusion criteria. All further articles were screened by one author (CJ). We included only empirical journal articles. Since our main focus was on the measurement of eye contact in human-human interaction, we used the following inclusion criteria: 
- Authors described "eye contact" or mutual gaze behavior to be a part of the primary aim or research question of the study.

- The study was focused on interaction between two real humans (i.e., no studies involving interaction between humans and animals or pictures).

- Human eye contact was assessed using quantitative measures.

- Methods to assess eye contact were specifically described in either the introduction, method, or results section.

We included studies on related concepts such as 'interpersonal looking' or 'visual regard' only if the authors additionally explicitly mentioned to focus on our focus of interest, i.e., 'eye contact'. Therefore, if authors were clearly focusing on 'eye contact', but did not mention these exact words but related terminology such as 'mutual gaze behavior between humans' a study was included.

After the initial screening of titles and abstracts, final eligibility of the articles was determined based on the full-text. Two authors screened the full texts independently (CJ, RH). Any discordances were resolved through discussion. For all included articles, data were subsequently extracted according to a predefined extraction form. The extracted data included study aim, study design, field of study, participant age group and health status, and study methodology-i.e., the definition and the operationalization of eye contact, and measures and techniques. See "Appendix 2" for the complete extraction form.

\section{Results}

\section{Study Selection}

The results of the search are summarized in Fig. 1 in accordance with the Preferred Reporting Items for Systematic Reviews and Meta-Analyses (PRISMA). The search yielded a total of 5583 unique articles. After initial screening, 224 articles were assessed based on the full-text and 109 studies met the inclusion criteria.

\section{Characteristics of the Included Studies}

Study characteristics $(N=109)$ are summarized in Table 1 . The studies were published between 1965 and 2017. Studies were performed mostly in the United States $(n=60)$ and European countries $(n=33)$. There were 80 experimental studies, one of which was a randomized controlled trial, and 29 were observational studies, of which 8 had a longitudinal design.

Studies included participants from various age groups: infants, children, adolescents, adults, and elderly; one study included a mixed cohort. Studies focused mostly on healthy participants. Other groups were patients with mental disorders, such as individuals diagnosed with autism spectrum disorder, or patients from specific patient populations, such as primary care patients.

The included studies focused on six sub-themes. The majority of studies assessed conversation dynamics, investigating the role of eye contact during conversations. Developmental studies focused on the role of eye contact during healthy infant and child development. Adult psychiatry studies assessed the role of eye contact in adult psychiatric disorders. Proximity studies examined its role in approaching or distancing behaviors. Studies in developmental psychopathology focused on the relationship between eye contact 

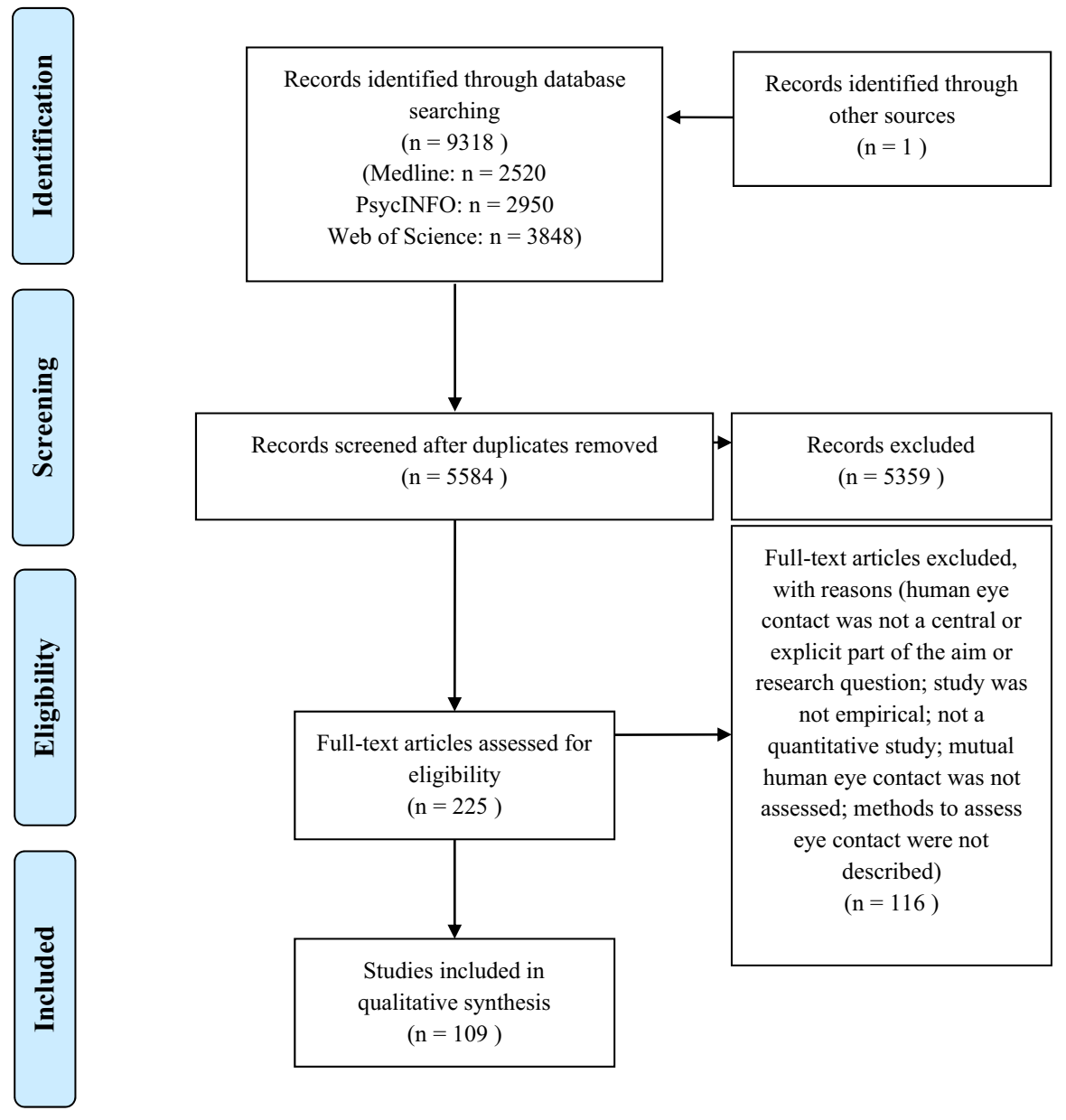

Fig. 1 PRISMA flowchart of included articles

and the development of psychiatric disorders in infants and children. Lastly, group dynamics studies investigated the role of eye contact within groups.

\section{Operationalization of Eye Contact in the Included Studies}

Two main approaches to assess eye contact were found: direct (eye contact is assessed while it occurs and is not retrospectively verifiable) and indirect (eye contact is registered and assessed after it has occurred and is therefore verifiable retrospectively). Within these two categories, eight specific techniques to assess eye contact could be distinguished. A description of each category and technique, with examples illustrating the variety of methodologies, is provided in Table 2.

There was wide variation across studies in how eye contact was defined, specifically regarding the reciprocity of eye contact. In studies using reciprocal measures $(n=45$ out 
Table 1 Characteristics of 109 included studies

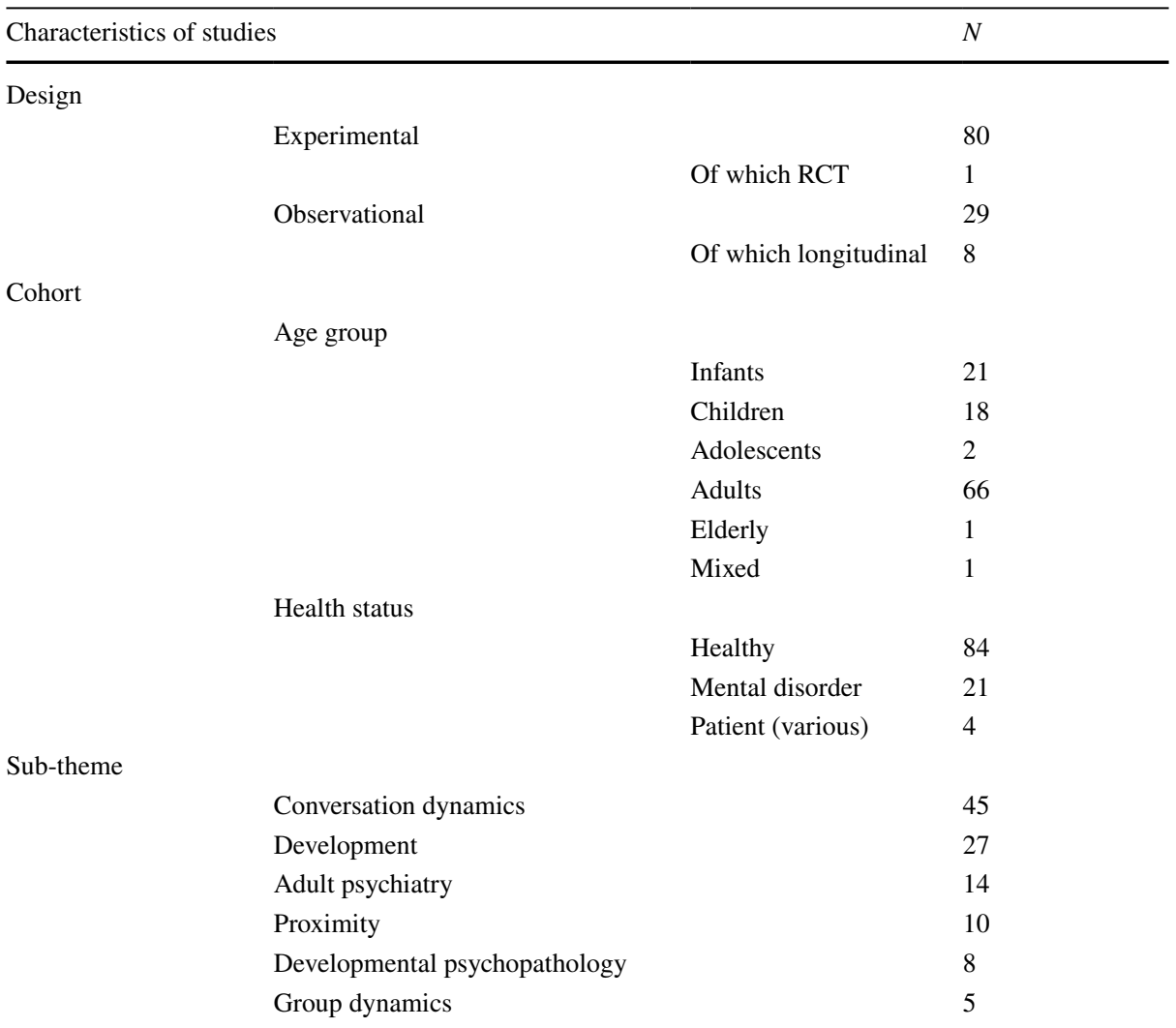

$R C T$ randomized controlled trial

of 109), eye contact was defined as situations in which one individual gazes at the other and vice versa simultaneously (i.e., two-way). In studies using non-reciprocal measures ( $n=43$ out of 109), eye contact was defined as situations in which one individual gazes at the other, irrespective of the other's gaze behavior (i.e., one-way). The remaining 21 studies did not specify the reciprocity of their measures.

Definitions additionally differed in the specific location to which gaze should be directed to be defined as eye contact. Twenty-nine studies specified that only gaze directed towards the eye-region was considered as eye contact. Twenty-six specified eye contact as gaze directed towards the face region. Nineteen defined eye contact more broadly as gaze directed towards another person. Two studies specified that gaze needed to be directed towards a general area, e.g., towards the interacting partner. Almost one third of the studies $(n=33)$ did not specify any region. 

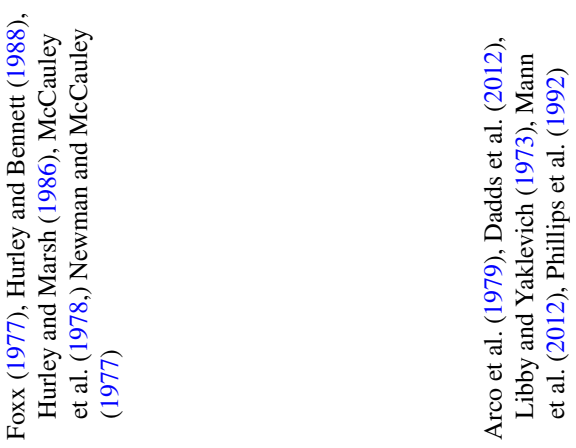

$\stackrel{\infty}{+}$ in

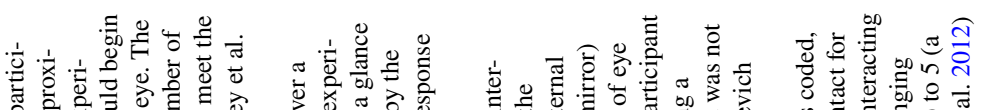

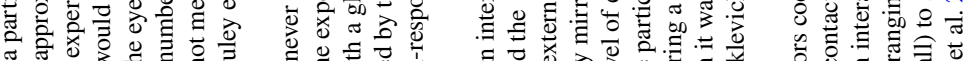

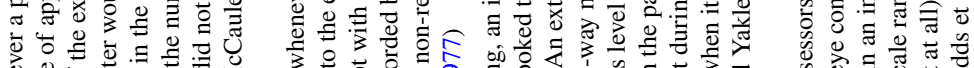

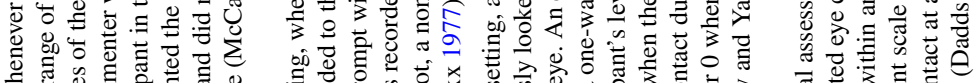

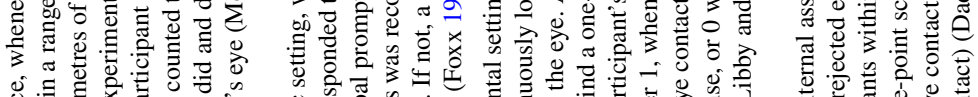

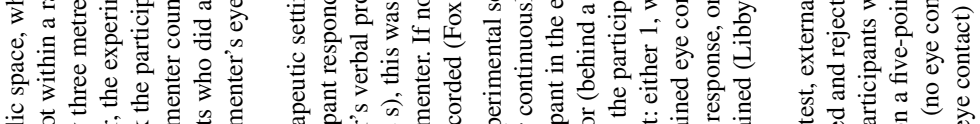

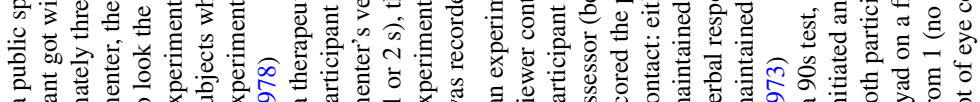

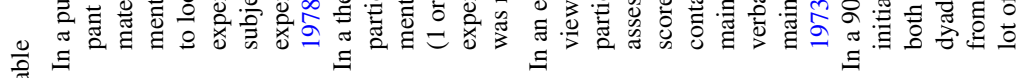

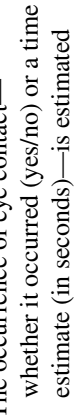

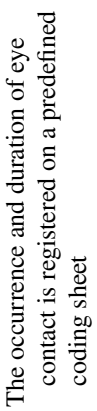

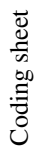




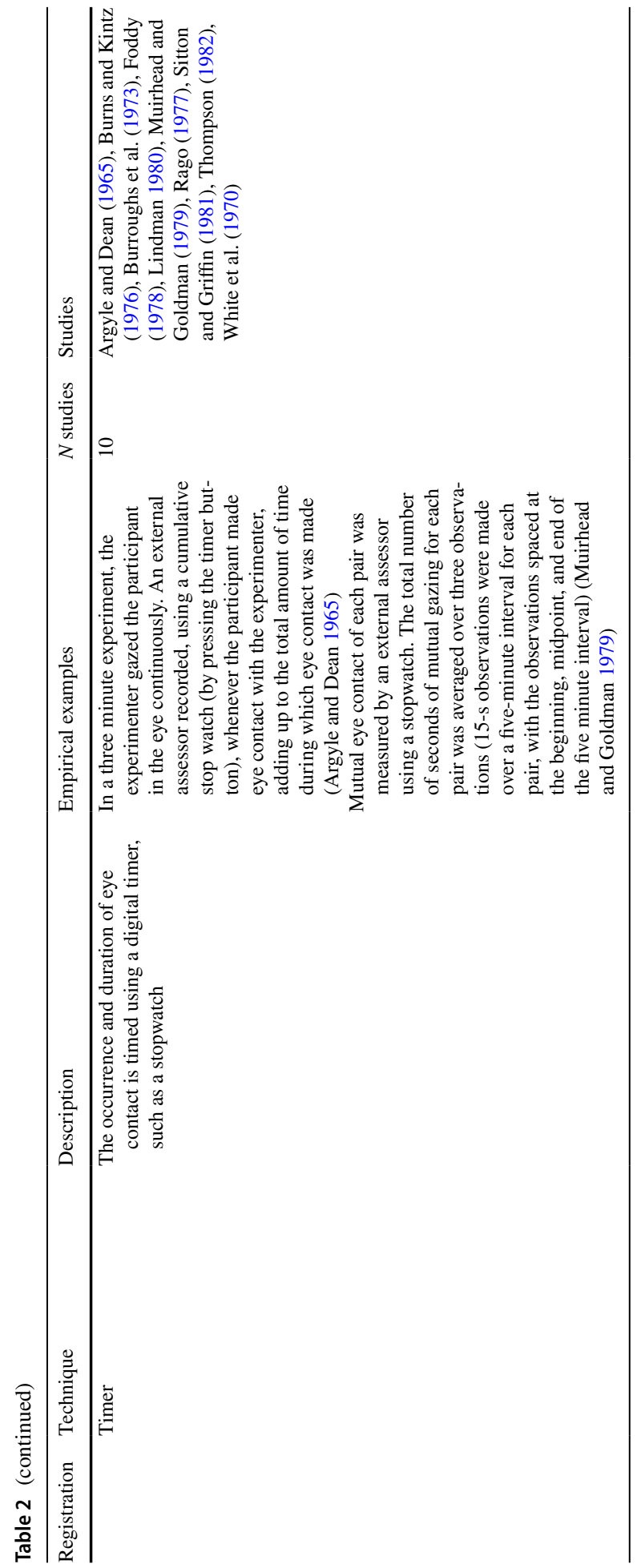




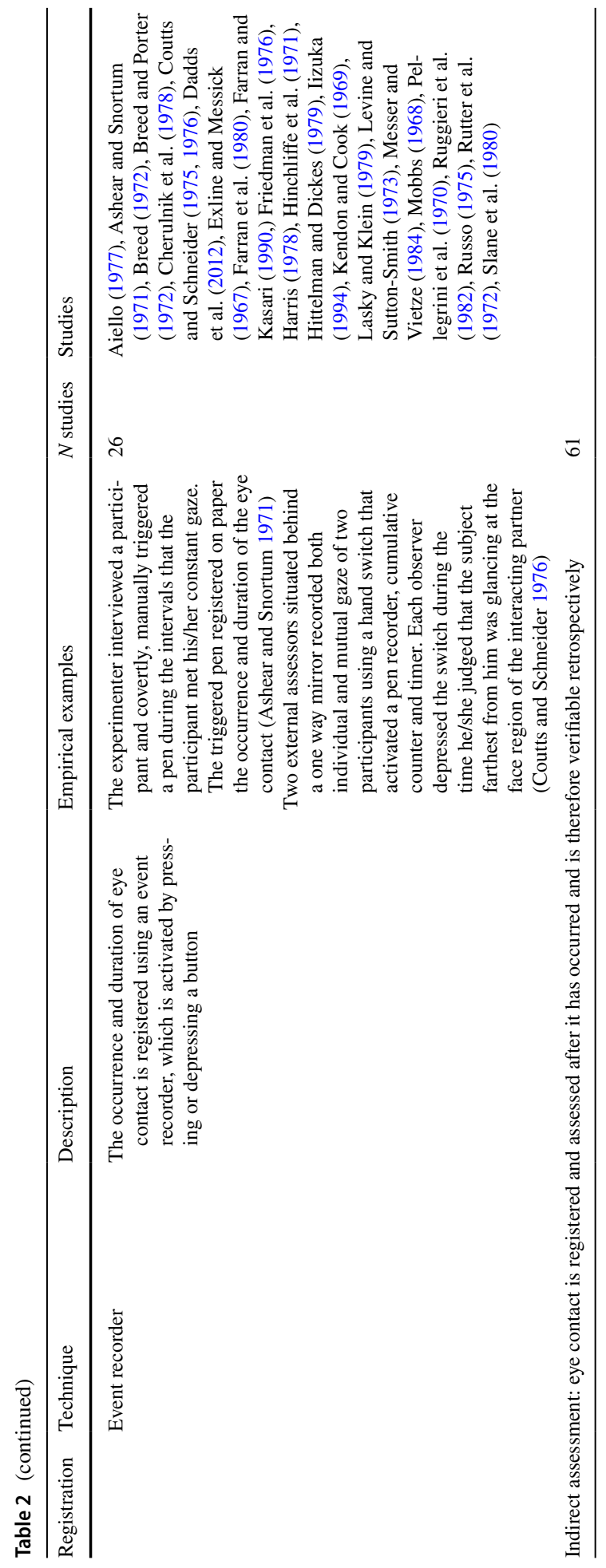




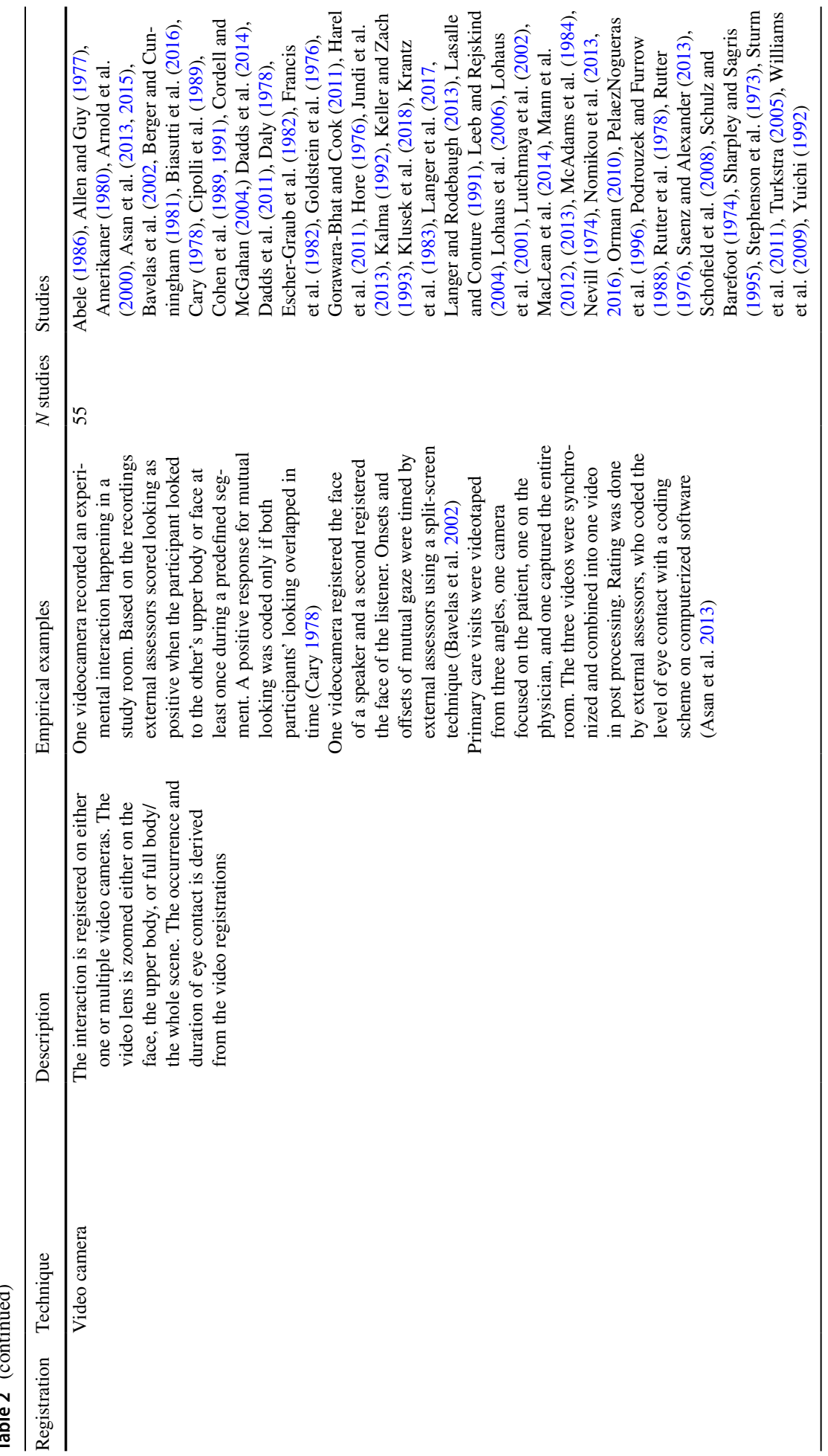




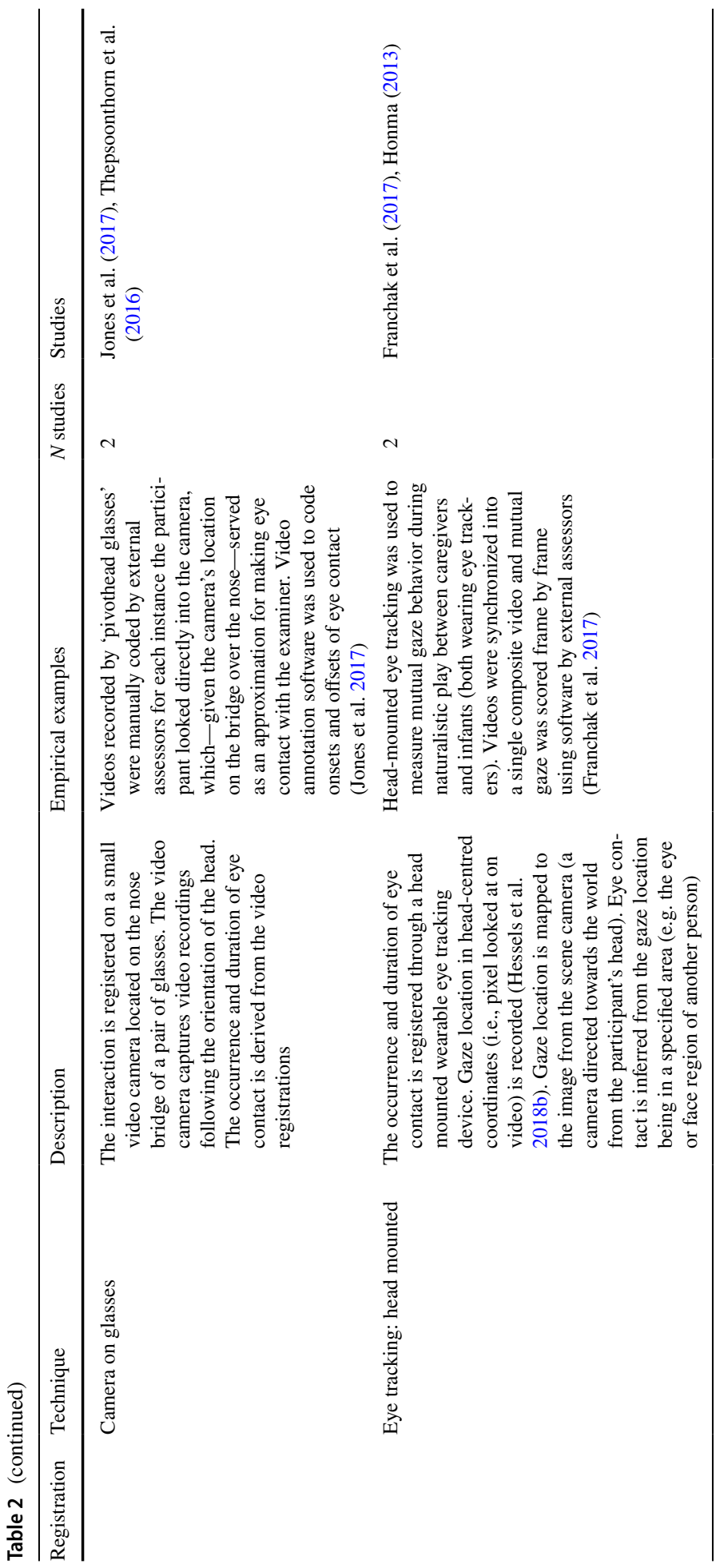




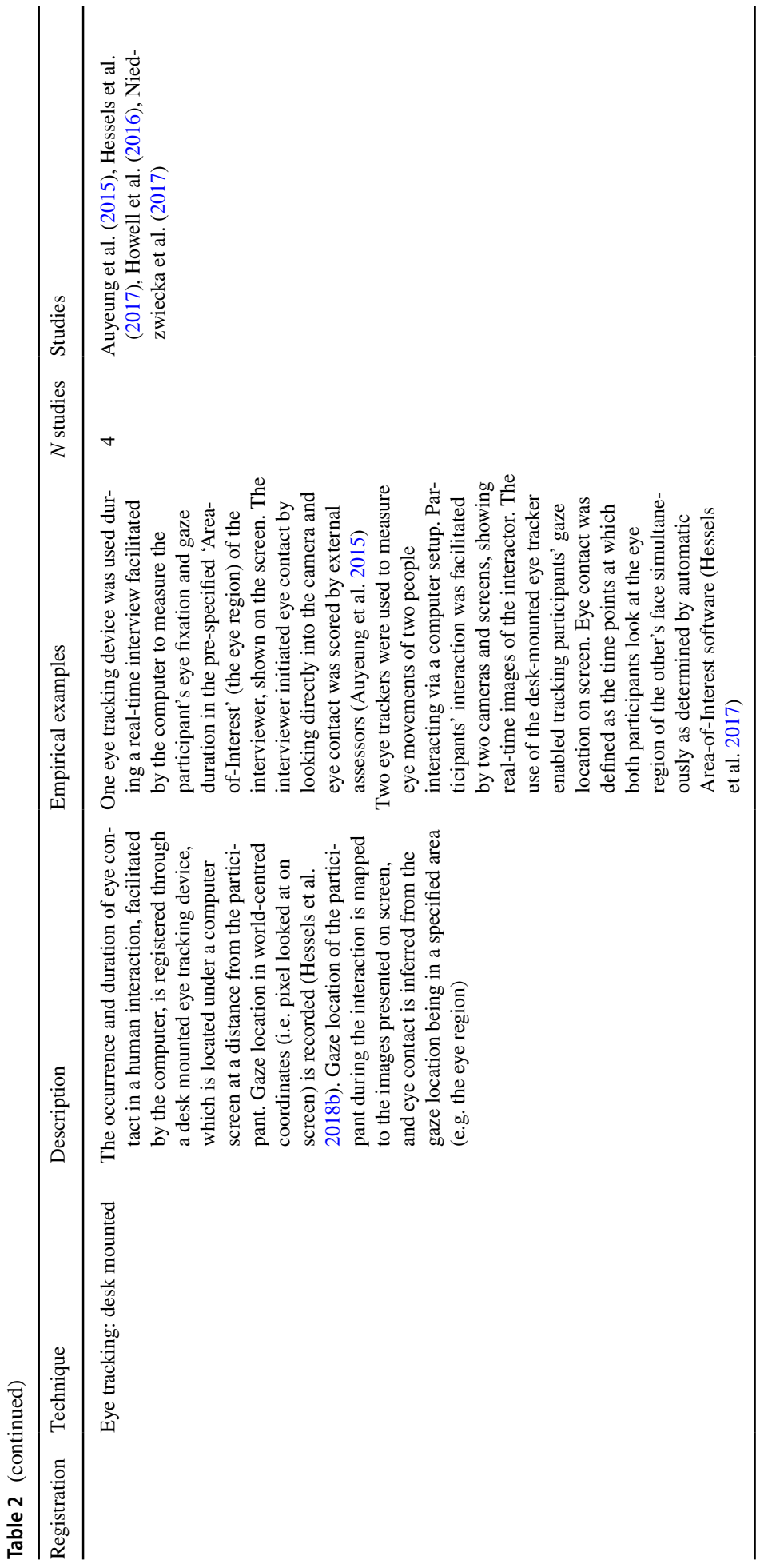




\section{Participant Behavior in the Included Studies}

Across included studies, eye contact was measured in relation to various behaviors and/ or tasks, i.e.:

- Natural behavior the participants carried out their regular activities as they would have done, had they not been involved in the research, usually in a familiar setting (e.g., at home). Their behaviors were observed and their amount of eye contact while doing so was measured. Examples of natural behavior in the included studies are mothers breastfeeding their children (Arco et al. 1979); patients visiting their physicians for a medical consultation (Asan et al. 2013); waiting room behavior (Cary 1978); and musicians performing at a concert (Biasutti et al. 2016).

- Interview participants responded to a set of questions asked by an interviewer, researcher, or confederate. An example is a study in which frequency of eye gaze while being interviewed was compared between anorexic young women and a control group (Cipolli et al. 1989).

- Assigned task participants were assigned a specific task, usually in an experimental setting. The most prevalent task was conducting a conversation on a topic specified by the researcher, e.g., self-disclosure (Amerikaner 1980). Examples of other tasks are: a bowling game (Iizuka 1994); a role play (Breed and Porter 1972); looking at one another (Hessels et al. 2017); and participating in a training (Hurley and Marsh 1986).

Other studies measured eye contact during behaviors that fit into several of the categories. Examples are studies where participants had to participate in an interview while performing a specific task, e.g., providing false answers (Jundi et al. 2013; Mann et al. 2013).

Remarkably, participants were rarely made aware of the fact that their gaze behavior was being observed; the majority of the studies included covertly measured eye contact.

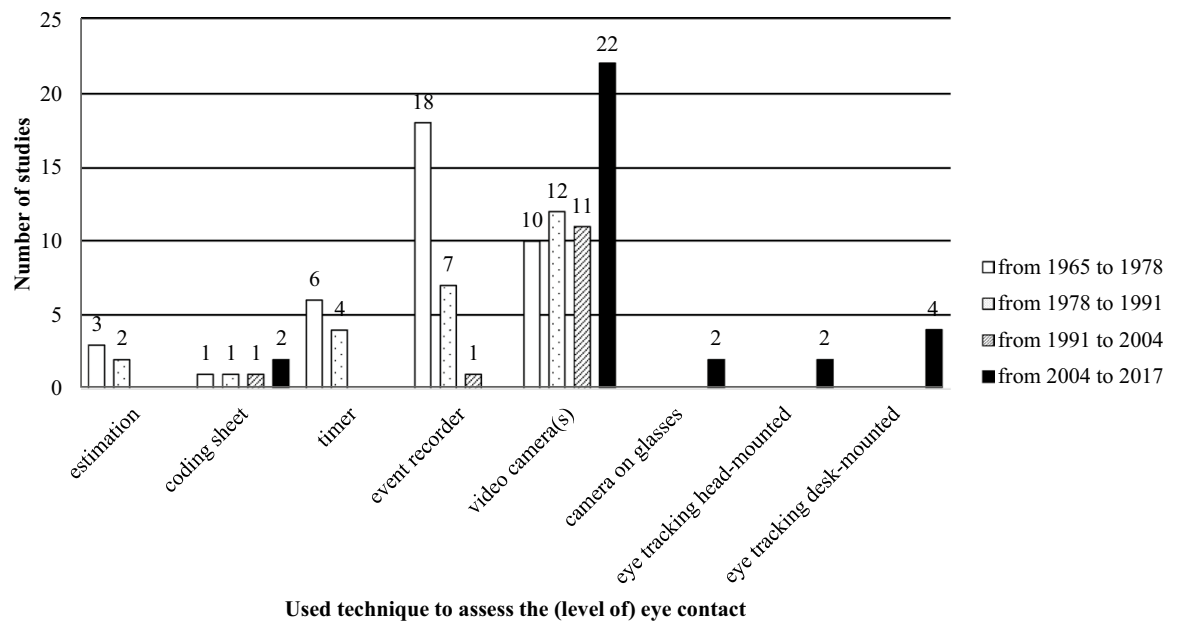

Fig. 2 Use of various techniques over different time periods 
Fig. 3 Decrease of assessor involvement in eye contact registration

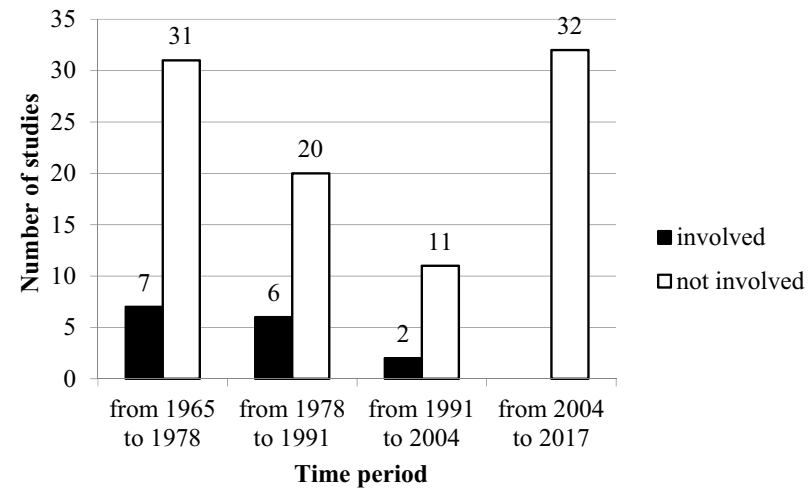

\section{Operationalization of Eye Contact over Time}

Figure 2 documents changes in the use of methodologies over time. The most frequently used method from 1965 to 1978 was the event recorder. The use of video camera(s) became more frequent between 1978 and 1991, and was still the most common method between 2004 and 2017. Recently, new techniques using camera on glasses and eye tracking have emerged. Between 2004 and 2017 coding sheets were used more frequently to assess eye contact compared to earlier time periods.

Over time, technical advances have resulted in eye contact measures that have become increasingly precise and accurate. Higher resolution has enabled more temporal and spatial precision. For instance, when estimating the total duration of eye contact based on observer judgment, one may estimate in minutes or perhaps seconds. Eye-tracking techniques enable estimates of eye contact duration in milliseconds (Hessels et al. 2017; Hurley and Marsh 1986). The same accounts for spatial resolution. A coding sheet may capture whether someone gazes towards the general face region, whereas eye tracking enables researchers to distinguish between gaze towards the right vs. the left eye (Hessels et al. 2017; Phillips et al. 1992).

Studies also differed regarding the involvement of the assessor in the actual eye contact. In 15 studies, the assessor was directly involved in establishing eye contact. For example, in multiple studies, the assessor served as interviewer and pressed a button on an event recorder whenever the interviewee looked them in the eyes. In the remaining 94 studies, assessors were not involved in the eye contact. For example, in multiple studies, independent assessors retrospectively scored the occurrence of eye contact based on video recordings of an interaction.

Figure 3 shows that the involvement of assessors in assessing eye contact has decreased over the years.

\section{Covariance Between Operationalization and Study Characteristics}

A frequency analysis of co-occurrences between participant age groups (adolescents; adults; children; elderly; infant; mixed) and operationalizations (study design; technique; moment of assessment; reciprocity; gaze location; involvement of the assessor) was performed (see "Appendix 3"). Few distinct patterns of co-occurrence were found, except for one: most observational studies were done with infants and children (18 out of 30) and 
most experimental studies were done with adults (56 out of 78). Next, a frequency analysis on co-occurrence of study field (approach-proximity; conversation; development; developmental psychiatry; group dynamics; psychiatry) with operationalizations was performed. Results again yielded few patterns, except that almost half of the observational studies (14 out of 30) were focused on (child) development whereas most experimental studies (39 out of 78) were focused on conversations.

It was not possible to quantitatively examine co-occurrence of research questions with methodology of the included studies, because of their high diversity.

\section{Discussion}

To create an overview of the various ways in which eye contact has been measured across disciplines we explored the assessment of eye contact in empirical studies. We identified 109 studies measuring eye-contact starting from 1965. We distinguished two categories of assessment, i.e., direct and indirect, and eight specific assessment techniques used within six different research disciplines. The identified techniques varied in spatial and temporal specificity, and in their reliance on human judgment.

Our results demonstrate a wide variety of methods to assess eye contact. Specifically, the eight identified techniques produce different outcomes. Estimation by a participant or observer yields a single indicator of eye contact occurrence. A coding sheet gives an assessor's estimation of the level of eye contact on a predefined scale. A timer provides a (cumulative) amount of duration, and an event recorder both frequency and duration of the level of eye contact. Video camera(s) yield any of the aforementioned outcomes and can additionally be used for retrospective assessment. A camera on glasses can additionally provide a mobile perspective. Head-mounted and desk-mounted eye-tracking techniques assess (mobile) time and frequency of fixations within a certain area of interest. These different techniques have evolved over time, increasing in temporal and spatial resolution. Eye-tracking yields more precise measurements than estimation or coding sheet techniques. Eye-tracking techniques also enable researchers to operationalize eye contact with more refined criteria, thereby facilitating replication studies.

Yet, the more novel techniques may not necessarily be the preferred techniques-they are often more expensive, require a different set of skills and have so far been time-intensive, limiting sample sizes (Franchak et al. 2017; Honma 2013). Yet, due to fast technological advances, eye tracking analysis is now becoming less time intensive, enabling larger sample sizes. Additionally, not every research question requires the precision that eye-tracking enables. In Table 3, we provide an overview of the possibilities offered by the various techniques, to provide some guidance in choosing the right technology for different types of research questions. Our recommendations are not definite. Researchers should choose what best suits their research question, population, and task. In their decisions, they can take into account factors such as obtrusiveness, interest in subjective experience or gaze location, and the required temporal and spatial resolution. For example, if the aim is to understand the gaze behavior of individuals diagnosed with autism spectrum and/or social anxiety disorders, researchers might want to take into account both frequency and duration of gaze towards the eye region, as these people may differ from healthy controls in dwell times and frequency of looking at the eyes (Auyeung et al. 2015; Hessels et al. 2018a). In people with social anxiety disorder, one might additionally want to assess their estimation of the level of eye contact in comparison to healthy controls, since their interpretation of eye contact might differ (Honma 2013). If the aim is to understand gaze behavior of 


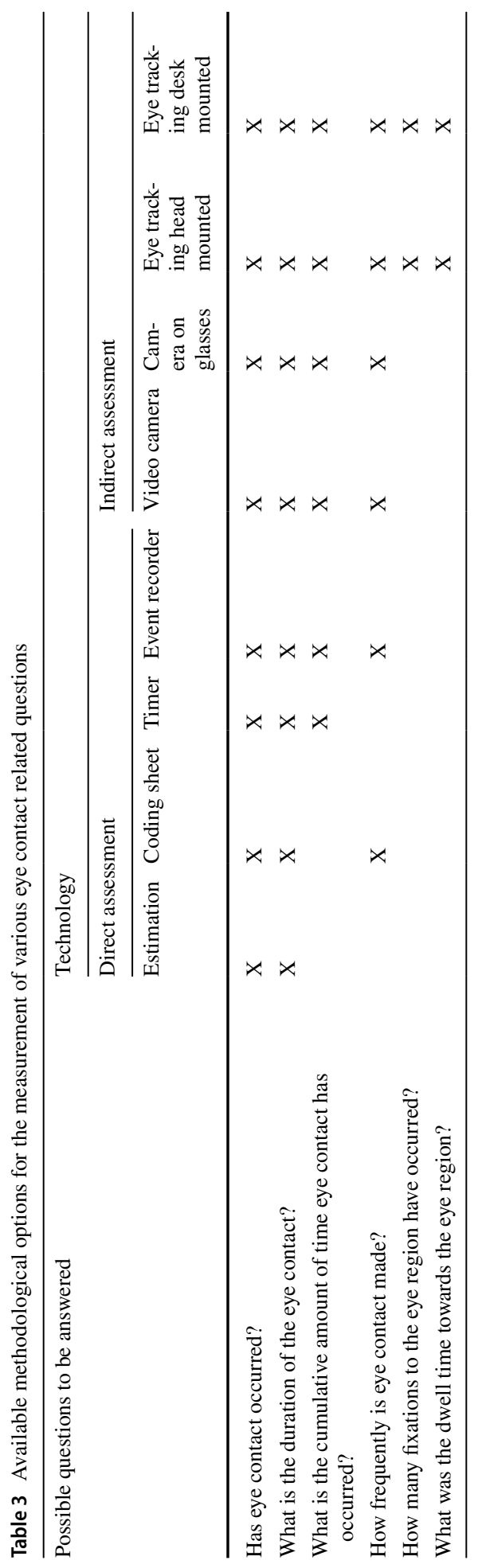


healthy neonates, observation with video cameras or coding sheets may be appropriate, as these are the least intrusive (Harel et al. 2011).

Our results show that the use of measures in which the assessor of the eye contact is involved as an interactor in the eye contact, which therefore cannot be verified afterwards, has decreased over time. Although their relative subjectivity may make these measures less reliable, they do justice to the definition of eye contact as a subjective perception of perceiving another person's gaze (Gamer and Hecht 2007).

People's experience of eye contact can be influenced by many factors, such as the presence of a third person, the distance from the other persons' face, or the perceiver's visual acuity (Gamer and Hecht 2007). We found that researchers often operationalize eye contact as being tied to a specific gaze location. Yet, this may not do justice to the personal experience of eye contact. It is known that humans are not always capable of judging when they are being looked at in the eyes. Particularly downward directions (i.e., towards the mouth) often still elicit the experience of eye contact (see Gamer and Hecht 2007). However, in specific cases, it could be relevant to focus on specific gaze locations such as the eye region, for example, when using the amount of eye contact as a diagnostic criterion for pathologies such as autism spectrum disorder. Whereas humans are usually unable to assess whether gaze is directed towards specific facial regions, novel measurement techniques like eye tracking are capable of doing so (Auyeung et al. 2015; Gamer and Hecht 2007).

If possible, future studies should combine measures that rely on personal experience of eye contact with techniques without the assessor's involvement in the eye contact registration, to determine (dis)congruence between their results. Such studies could, for example, investigate to what extent gaze location reflects people's subjective experience of eye contact.

When investigating eye contact, researchers should choose their methods based on what best fits their research aim and population. For example, the subjective experiences of neonates are obviously impossible to assess, whereas in psychiatric populations it may be very insightful to measure people's personal experience of eye contact. This aligns with our finding that studies involving infants and children were almost always observational, whereas the experimental studies more often included adult populations.

Our results demonstrate that studies assessing eye contact are heterogeneous, not only in measurement methods, but also regarding study populations and the behaviors that were studied. Such behaviors ranged from naturally occurring conduct, through being interviewed, to assigned tasks such as conversation, games, or trainings. The most coherent group of behavioral tasks studied was identified in developmental psychology and involved observational, naturally occurring behavior of infants. Overall, however, the wide heterogeneity in tasks, outcomes and operationalizations prevents researchers from comparing findings regarding eye contact across studies.

To our knowledge, only two studies have compared eye-contact measures, examining the differences between observer and participant rating (Edmunds et al. 2017; Shaw et al. 1971). One of these found weaker correlations between observer and participant eye contact ratings, than between multiple observer ratings (Shaw et al. 1971). The other study found that using a standing video camera was less reliable than using camera on glasses (Edmunds et al. 2017). Other studies evaluated the reliability and validity of measuring eye contact using either observer ratings (Knight et al. 1973) or video coding (Beattie and Bogle 1982). All of those concluded that there were methodological issues with the studied techniques. For example, when using observer ratings, the distance between observer and participants was found to affect the rating reliability (Knight et al. 1973). When using video cameras, using two cameras (each focused on one of the interactors' faces), combined in a split-screen was found to be more reliable than using one camera only or two cameras with greater distance (Beattie and Bogle 1982). More studies comparing 
multiple measures to assess eye contact are needed to provide researchers with guidance in choosing optimal measures for their particular study aim. Furthermore, such comparative research would provide insight into the interpretability of eye contact measures, facilitating the interpretation of both previous and future studies. In addition to choosing between measurement techniques, researchers also need to decide on their specific outcome operationalization. For example, when using eye-tracking, both frequency and duration of eye contact have been used. How precisely to interpret the associated outcomes is not clear yet. For example, a person who makes very frequent, brief eye contact may either be perceived as attentive or as restless. How frequency and duration relate to each other, remains to be determined in methodological research.

A surprising finding is that only a few studies include a detailed description of their methods for assessing eye contact. We excluded studies that did not explicitly describe their measures. Still, $31 \%$ of the included studies lacked a specific description of the target gaze region of the supposed eye contact. Moreover, in 19\% of the studies, it was unclear whether eye contact was operationalized as reciprocal or not. As a consequence, we cannot assess the comparability of studies aiming to measure eye contact. The use of different measures could signify that different studies are investigating different things. For instance, a study measuring unidirectional eye contact using a scale might yield completely different results than a study measuring reciprocal eye contact with desk-mounted eye tracking.

The issue of comparability may, in reality, be even more profound than identified in our review. We included only research focused on 'eye contact', not on related phenomena, and excluded any research on eye contact that did not involve (at least) two human beings. In the research we excluded, even more ways to measure eye contact may have been employed. An example is research instructing individuals to make eye contact with an experimenter in an experimental condition, after which researchers make inferences about whether eye contact has taken place, albeit without formal measurement: (Ponkanen and Hietanen 2012). Other studies outside of the current review's scope have, for example, instructed participants to look at pictures of faces, using their gaze behavior as a model system for studying human social interaction (Senju and Johnson 2009b). This even greater heterogeneity in measurement could lead to incoherent research findings and conclusions. Future studies should precisely define and operationalize eye contact to enhance interpretation and comparability across studies.

Our conclusions should be interpreted in light of some limitations. First, we did not assess the quality of the included studies, given that our primary focus was to analyze the methodology used to assess eye contact. It is thus possible that the quality of the included studies varies, especially taking into account they date back as far as 1965 . However, we believe that giving a broad and historical perspective on the methodologies used to study eye contact justifies our choice. Second, we selected peer-reviewed articles in English only and therefore excluded published articles in other languages.

\section{Conclusion}

In this review, we have highlighted the methodological diversity of measures to asses eye contact between two human beings. Of particular importance for future work is how various operationalizations of eye contact-such as the personal experience of eye contact or the more precise measures assessing gaze location-can be used to better understand the phenomenon of eye contact and its consequences for human interaction. To do this, research is needed that captures both the first-person experience of eye contact and the more objective outsiders' perspective. Researchers need to make their choices for specific definitions and operationalizations of 
eye contact well-founded, based on evidence or theory. Future studies would benefit from specific descriptions of which techniques were used, the direction of gaze (reciprocal or not), the area of interest of the gaze direction (eyes, face, body or person), and the participant behavior. Moreover, a more meticulous investigation of the comparability of measures is needed before conclusions can be drawn and theories formed about the workings of eye contact.

Open Access This article is licensed under a Creative Commons Attribution 4.0 International License, which permits use, sharing, adaptation, distribution and reproduction in any medium or format, as long as you give appropriate credit to the original author(s) and the source, provide a link to the Creative Commons licence, and indicate if changes were made. The images or other third party material in this article are included in the article's Creative Commons licence, unless indicated otherwise in a credit line to the material. If material is not included in the article's Creative Commons licence and your intended use is not permitted by statutory regulation or exceeds the permitted use, you will need to obtain permission directly from the copyright holder. To view a copy of this licence, visit http://creativecommons.org/licenses/by/4.0/.

\section{Appendix 1}

Used search strings per database.

\begin{tabular}{|c|c|c|c|}
\hline Date and time: & \multicolumn{3}{|l|}{$8-2-201810.55$} \\
\hline \multicolumn{4}{|c|}{$\begin{array}{l}\text { Ovid MEDLINE(R) Epub Ahead of Print, In-Process and Other Non-Indexed Citations, Ovid } \\
\text { MEDLINE(R) Daily and Ovid MEDLINE(R) } 1946 \text { to Present }\end{array}$} \\
\hline 1 & Eye contact.ab,kf,ti & 1118 & \\
\hline 2 & $\begin{array}{l}\text { ((Gaze or gazing) adj3 (direct or mutual } \\
\text { or dyadic or eye) }) \cdot \mathrm{ab}, \mathrm{kf}, \mathrm{ti}\end{array}$ & 1904 & \\
\hline 3 & Animals/ not humans/ & $4,390,128$ & \\
\hline 4 & 1 or 2 & 2829 & \\
\hline 5 & 4 not 3 & 2642 & \\
\hline 6 & Limit 3 to English language & 2538 & \\
\hline 7 & Limit 6 to journal article & 2520 & \\
\hline Date and time: & 8-2-2018 10.38 & & \\
\hline \multicolumn{4}{|c|}{ PsycINFO 1806 to January Week 52018} \\
\hline 1 & Eye contact/ & 926 & \\
\hline 2 & Eye contact.ab,id,ti & 1837 & \\
\hline 3 & $\begin{array}{l}\text { ((Gaze or gazing) adj3 (direct or mutual } \\
\text { or dyadic or eye)).ab,id,ti }\end{array}$ & 2100 & \\
\hline 4 & Animals/ not humans/ & 7025 & \\
\hline 5 & 1 or 2 or 3 & 3938 & \\
\hline 6 & 4 not 5 & 3934 & \\
\hline 7 & Limit 6 to English language & 3713 & \\
\hline 8 & Limit 7 to "0110 peer-reviewed journal" & 2950 & \\
\hline Date and time: & $8-2-201811.04$ & & \\
\hline \multicolumn{4}{|l|}{ Web of Science } \\
\hline 1 & TOPIC: ("eye contact") & 1528 & $\begin{array}{c}\text { Indexes = SCI- } \\
\text { EXPANDED, } \\
\text { SSCI, A\&HCI, } \\
\text { ESCI Times- } \\
\text { pan = All years }\end{array}$ \\
\hline
\end{tabular}




\begin{tabular}{|c|c|c|c|}
\hline 2 & $\begin{array}{l}\text { TOPIC: (((gaze OR gazing) NEAR/2 } \\
\text { (direct OR mutual OR dyadic OR } \\
\text { eye))) }\end{array}$ & 3179 & $\begin{array}{c}\text { Indexes }=\text { SCI- } \\
\text { EXPANDED, } \\
\text { SSCI, A\&HCI, } \\
\text { ESCI Times- } \\
\text { pan = All years }\end{array}$ \\
\hline 3 & $\# 1$ OR \#2 & 4403 & $\begin{array}{c}\text { Indexes }=\text { SCI- } \\
\text { EXPANDED, } \\
\text { SSCI, A\&HCI, } \\
\text { ESCI Times- } \\
\text { pan = All years }\end{array}$ \\
\hline 4 & $\begin{array}{l}\text { Refined by: LANGUAGES: (ENGLISH) } \\
\text { AND DOCUMENT TYPES: (ARTI- } \\
\text { CLE) }\end{array}$ & 3848 & $\begin{array}{c}\text { Indexes }=\text { SCI- } \\
\text { EXPANDED, } \\
\text { SSCI, A\&HCI, } \\
\text { ESCI Times- } \\
\text { pan = All years }\end{array}$ \\
\hline Tot & & 9318 & \\
\hline \multicolumn{2}{|c|}{ After deduplication in EndNote: } & 5583 & \\
\hline
\end{tabular}

The terms 'direct', 'mutual' and 'dyadic' combined with 'gaze' or 'gazing' are often used as a synonym for eye contact

\section{Appendix 2}

Predefined extraction form
a. Authors
b. Year of publication
c. Journal
d. Study aim (or research question)
e. Study design
f. Study setting

- Country

g. Sample (describe when possible: number of participants, number of groups, age category (infant/children/adolescents/adults/elderly), healthy or diagnosis)

h. Study methodology

- Definition/operationalization of eye contact

- Description of used measurements

i. Participant behavior

j. Remarks

\section{Appendix 3}

Tables of co-occurrences of age group versus operationalisation and field of study vs. operationalisation. 


\begin{tabular}{|c|c|c|c|c|c|c|c|c|}
\hline \multirow[b]{3}{*}{ Age group } & \multicolumn{8}{|c|}{ Operationalisation } \\
\hline & \multicolumn{8}{|l|}{ Technique } \\
\hline & Estimation & $\begin{array}{l}\text { Coding } \\
\text { sheet }\end{array}$ & Timer & $\begin{array}{l}\text { Event } \\
\text { recorder }\end{array}$ & $\begin{array}{l}\text { Video } \\
\text { camera(s) }\end{array}$ & $\begin{array}{l}\text { Cam- } \\
\text { era on } \\
\text { glasses }\end{array}$ & $\begin{array}{l}\text { Eye track- } \\
\text { ing head- } \\
\text { mounted }\end{array}$ & $\begin{array}{l}\text { Eye tracking } \\
\text { desk- } \\
\text { mounted }\end{array}$ \\
\hline $\begin{array}{l}\text { Adoles- } \\
\text { cents }\end{array}$ & 0 & 0 & 0 & 0 & 2 & 0 & 0 & 0 \\
\hline Adults & 4 & 2 & 9 & 17 & 29 & 1 & 1 & 3 \\
\hline Children & 1 & 1 & 0 & 5 & 10 & 1 & 0 & 0 \\
\hline Elderly & 0 & 0 & 0 & 0 & 1 & 0 & 0 & 0 \\
\hline Infant & 0 & 2 & 0 & 4 & 13 & 0 & 1 & 1 \\
\hline Mixed & 0 & 0 & 1 & 0 & 0 & 0 & 0 & 0 \\
\hline
\end{tabular}

\begin{tabular}{|c|c|c|c|c|c|}
\hline & \multicolumn{5}{|c|}{ Area of the direction of gaze } \\
\hline & NA & Face & Eyes & Area & Partner \\
\hline Adolescents & 0 & 1 & 1 & 0 & 0 \\
\hline Adults & 24 & 10 & 19 & 2 & 11 \\
\hline Children & 5 & 5 & 4 & 0 & 4 \\
\hline Elderly & 0 & 1 & 0 & 0 & 0 \\
\hline Infant & 4 & 9 & 5 & 0 & 3 \\
\hline \multirow[t]{3}{*}{ Mixed } & 0 & 0 & 0 & 0 & 1 \\
\hline & \multicolumn{5}{|c|}{ Reciprocity of gaze } \\
\hline & \multicolumn{2}{|l|}{ One-way } & Two-way & \multicolumn{2}{|l|}{ NA } \\
\hline Adolescents & \multicolumn{2}{|l|}{1} & 1 & \multicolumn{2}{|l|}{0} \\
\hline Adults & 28 & \multicolumn{2}{|c|}{23} & \multicolumn{2}{|l|}{15} \\
\hline Children & 5 & \multicolumn{2}{|c|}{9} & \multicolumn{2}{|l|}{4} \\
\hline Elderly & 1 & \multicolumn{2}{|c|}{0} & \multicolumn{2}{|l|}{0} \\
\hline Infant & 7 & \multicolumn{2}{|c|}{12} & \multicolumn{2}{|l|}{2} \\
\hline \multirow[t]{3}{*}{ Mixed } & 1 & \multicolumn{2}{|c|}{0} & \multicolumn{2}{|l|}{0} \\
\hline & \multicolumn{5}{|c|}{ Study design } \\
\hline & \multicolumn{5}{|c|}{ Observational $\quad$ Experimental } \\
\hline Adolescents & \multicolumn{2}{|l|}{0} & 2 & & \\
\hline Adults & 10 & \multicolumn{2}{|c|}{56} & & \\
\hline Children & 6 & \multicolumn{2}{|c|}{12} & & \\
\hline Elderly & 1 & \multicolumn{2}{|c|}{0} & & \\
\hline Infant & 12 & \multicolumn{2}{|c|}{9} & & \\
\hline \multirow[t]{3}{*}{ Mixed } & 1 & \multicolumn{2}{|c|}{0} & & \\
\hline & \multicolumn{5}{|c|}{ Involvement of assessor } \\
\hline & Involved & & olved & & \\
\hline Adolescents & 0 & & & & \\
\hline Adults & 9 & 5 & & & \\
\hline Children & 2 & 1 & & & \\
\hline Elderly & 0 & & & & \\
\hline
\end{tabular}




\begin{tabular}{lll}
\hline & \multicolumn{2}{l}{ Involvement of assessor } \\
\cline { 2 - 3 } & Involved & Not involved \\
\hline Infant & 4 & 17 \\
Mixed & 0 & 1 \\
\hline & Moment of assessment \\
\cline { 2 - 3 } & Indirect & Direct \\
\hline Adolescents & 2 & 0 \\
Adults & 37 & 29 \\
Children & 11 & 7 \\
Elderly & 1 & 0 \\
Infant & 14 & 7 \\
Mixed & 0 & 1 \\
\hline
\end{tabular}

Numbers in the table represent the number of studies for each category

\section{References}

Abele, A. (1986). Functions of gaze in social interaction: Communication and monitoring. Journal of Nonverbal Behavior, 10(2), 83-101. https://doi.org/10.1007/BF01000006.

Aiello, J. R. (1977). A further look at equilibrium theory: Visual interaction as a function of interpersonal distance. Environmental Psychology \& Nonverbal Behavior, 1(2), 122-140. https://doi. org/10.1007/BF01145461.

Allen, D. E., \& Guy, R. F. (1977). Ocular breaks and verbal output. Sociometry, 40(1), 90-96. https:// doi.org/10.2307/3033550.

Amerikaner, M. (1980). Self-disclosure: A study of verbal and coverbal intimacy. The Journal of Psychology: Interdisciplinary and Applied, 104(2), 221-231.

Arco, C. M., Self, P. A., \& Gutrecht, N. (1979). The effect of increased maternal visual regard on neonatal visual behavior. Journal of Clinical Child Psychology, 8(2), 117-120. https://doi. org/10.1080/15374417909532899.

Argyle, M., \& Dean, J. (1965). Eye-contact, distance and affiliation. Sociometry, 28, 289-304.

Arnold, A., Semple, R. J., Beale, I., \& Fletcher-Flinn, C. M. (2000). Eye contact in children's social interactions: What is normal behavior? Journal of Intellectual and Developmental Disability, 25(3), 207-216. https://doi.org/10.1080/13269780050144271.

Asan, O., Xu, J., \& Montague, E. (2013). Dynamic comparison of physicians' interaction style with electronic health records in primary care settings. Journal of General Practice, 2, 10.

Asan, O., Young, H. N., Chewning, B., \& Montague, E. (2015). How physician electronic health record screen sharing affects patient and doctor non-verbal communication in primary care. Patient Education and Counseling, 98(3), 310-316. https://doi.org/10.1016/j.pec.2014.11.024.

Ashear, V., \& Snortum, J. R. (1971). Eye contact in children as a function of age, sex, social and intellective variables. Developmental Psychology, 4(3), 479. https://doi.org/10.1037/h0030974.

Auyeung, B., Lombardo, M. V., Heinrichs, M., Chakrabarti, B., Sule, A., Deakin, J. B., et al. (2015). Oxytocin increases eye contact during a real-time, naturalistic social interaction in males with and without autism. Translational Psychiatry. https://doi.org/10.1038/tp.2014.146.

Bavelas, J. B., Coates, L., \& Johnson, T. (2002). Listener responses as a collaborative process: The role of gaze. Journal of Communication, 52(3), 566-580. https://doi.org/10.1111/j.1460-2466.2002. tb02562.x.

Beattie, G. W., \& Bogle, G. (1982). The reliability and validity of different video-recording techniques used for analysing gaze in dyadic interaction. British Journal of Social Psychology, 21(1), 31-34. https://doi.org/10.1111/j.2044-8309.1982.tb00509.x.

Berger, J., \& Cunningham, C. (1981). The development of eye contact between mothers and normal versus Down's syndrome infants. Developmental Psychology, 17(5), 678-689. https://doi. org/10.1037/0012-1649.17.5.678. 
Biasutti, M., Concina, E., Wasley, D., \& Williamon, A. (2016). Music regulators in two string quartets: A comparison of communicative behaviors between low- and high-stress performance conditions. Frontiers in Psychology. https://doi.org/10.3389/fpsyg.2016.01229.

Breed, G. (1972). The effect of intimacy: Reciprocity or retreat? British Journal of Social \& Clinical Psychology, 11(2), 135-142. https://doi.org/10.1111/j.2044-8260.1972.tb00794.x.

Breed, G., \& Porter, M. (1972). Eye contact, attitudes, and attitude change among males. The Journal of Genetic Psychology: Research and Theory on Human Development, 120(2), 211-217. https://doi. org/10.1080/00221325.1972.10532234.

Burns, J. A., \& Kintz, B. L. (1976). Eye contact while lying during an interview. Bulletin of the Psychonomic Society, 7(1), 87-89. https://doi.org/10.3758/bf03337131.

Burroughs, W., Schultz, W., \& Autrey, S. (1973). Quality of argument, leadership votes, and eye contact in three-person leaderless groups. Journal of Social Psychology, 90(1), 89-93.

Cary, M. S. (1978). The role of gaze in the initiation of conversation. Social Psychology, 41(3), 269271. https://doi.org/10.2307/3033565.

Cherulnik, P. D., Neely, W. T., Flanagan, M., \& Zachau, M. (1978). Social skill and visual interaction. The Journal of Social Psychology, 104(2), 263-270. https://doi.org/10.1080/00224 545.1978.9924068.

Cipolli, C., Sancini, M., Tuozzi, G., Bolzani, R., Mutinelli, P., Flamigni, C., et al. (1989). Gaze and eyecontact with anorexic adolescents. British Journal of Medical Psychology, 62, 365-369. https://doi. org/10.1111/j.2044-8341.1989.tb02846.x.

Cohen, I. L., Vietze, P. M., Sudhalter, V., Jenkins, E. C., \& Brown, W. T. (1989). Parent-child dyadic gaze patterns in fragile $\mathrm{X}$ males and in non-fragile X males with autistic disorder. Journal of Child Psychology \& Psychiatry \& Allied Disciplines, 30(6), 845-856.

Cohen, I. L., Vietze, P. M., Sudhalter, V., Jenkins, E. C., \& Brown, W. T. (1991). Effects of age and communication level on eye contact in fragile $\mathrm{X}$ males and non-fragile $\mathrm{X}$ autistic males. American Journal of Medical Genetics, 38(2-3), 498-502.

Cordell, D. M., \& McGahan, J. R. (2004). Mutual gaze duration as a function of length of conversation in male-female dyads. Psychological Reports, 94(1), 109-114.

Coutts, L. M., \& Schneider, F. W. (1975). Visual behavior in an unfocused interaction as a function of sex and distance. Journal of Experimental Social Psychology, 11(1), 64-77. https://doi.org/10.1016/ S0022-1031\%2875\%2980010-2.

Coutts, L. M., \& Schneider, F. W. (1976). Affiliative conflict theory: An investigation of the intimacy equilibrium and compensation hypothesis. Journal of Personality and Social Psychology, 34(6), 11351142. https://doi.org/10.1037/0022-3514.34.6.1135.

Dadds, M. R., Allen, J. L., McGregor, K., Woolgar, M., Viding, E., \& Scott, S. (2014). Callous-unemotional traits in children and mechanisms of impaired eye contact during expressions of love: A treatment target? Journal of Child Psychology and Psychiatry, 55(7), 771-780. https://doi.org/10.1111/jcpp.12155.

Dadds, M. R., Allen, J. L., Oliver, B. R., Faulkner, N., Legge, K., Moul, C., et al. (2012). Love, eye contact and the developmental origins of empathy v. psychopathy. British Journal of Psychiatry, 200(3), 191-196. https://doi.org/10.1192/bjp.bp.110.085720.

Dadds, M. R., Jambrak, J., Pasalich, D., Hawes, D. J., \& Brennan, J. (2011). Impaired attention to the eyes of attachment figures and the developmental origins of psychopathy. Journal of Child Psychology and Psychiatry, 52(3), 238-245. https://doi.org/10.1111/j.1469-7610.2010.02323.x.

Daly, S. (1978). Behavioural correlates of social anxiety. British Journal of Social \& Clinical Psychology, 17(2), 117-120. https://doi.org/10.1111/j.2044-8260.1978.tb00252.x.

Edmunds, S. R., Rozga, A., Li, Y., Karp, E. A., Ibanez, L. V., Rehg, J. M., et al. (2017). Brief report: Using a point-of-view camera to measure eye gaze in young children with autism spectrum disorder during naturalistic social interactions: A pilot study. Journal of Autism and Developmental Disorders, 47(3), 898-904.

Escher-Graub, D., Morath, M., \& Todt, D. (1982). Timing of visual interaction between infants and an approaching stranger. Infant Behavior \& Development, 5(2), 203-207. https://doi.org/10.1016/S0163 $-6383 \% 2882 \% 2980029-5$.

Exline, R. V., \& Messick, D. (1967). The effects of dependency and social reinforcement upon visual behaviour during an interview. British Journal of Social \& Clinical Psychology, 6(4), 256-266. https://doi. org/10.1111/j.2044-8260.1967.tb00528.x.

Farber, N. J., Liu, L., Chen, Y., Calvitti, A., Street, R. L., Zuest, D., et al. (2015). EHR use and patient satisfaction: What we learned. Journal of Family Practice, 64(11), 687-696.

Farran, D. C., Hirschbiel, P., \& Jay, S. (1980). Toward interactive synchrony: The gaze patterns of mothers and children in three age groups. International Journal of Behavioral Development, 3(2), 215-224. https://doi.org/10.1177/016502548000300206. 
Farran, D. C., \& Kasari, C. (1990). A longitudinal analysis of the development of synchrony in mutual gaze in mother-child dyads. Journal of Applied Developmental Psychology, 11(4), 419-430. https://doi. org/10.1016/0193-3973\%2890\%2990018-F.

Farroni, T., Csibra, G., Simion, F., \& Johnson, M. H. (2002). Eye contact detection in humans from birth. Proceedings of the National Academy of Sciences, 99(14), 9602-9605.

Foddy, M. (1978). Patterns of gaze in cooperative and competitive negotiation. Human Relations, 31(11), 925-938.

Foxx, R. M. (1977). Attention training: The use of overcorrection avoidance to increase the eye contact of autistic and retarded children. Journal of Applied Behavior Analysis, 10(3), 489-499.

Franchak, J. M., Kretch, K. S., \& Adolph, K. E. (2017). See and be seen: Infant-caregiver social looking during locomotor free play. Developmental Science, 26, 26. https://doi.org/10.1111/desc.12626.

Francis, P. L., Self, P. A., \& Noble, C. A. (1982). Maternal verbal control techniques with you infants during mutual gaze and visual co-orientation episodes. International Journal of Behavioral Development, 5(3), 317-327. https://doi.org/10.1177/016502548200500303.

Friedman, S., Thompson, M. A., Crawley, S., Criticos, A., Drake, D., Iacobbo, M., et al. (1976). Mutual visual regard during mother-infant play. Perceptual and Motor Skills, 42(2), 427-431.

Gamer, M., \& Hecht, H. (2007). Are you looking at me? Measuring the cone of gaze. Journal of Experimental Psychology: Human Perception and Performance, 33(3), 705.

Goldstein, M. A., Kilroy, M. C., \& Van de Voort, D. (1976). Gaze as a function of conversation and degree of love. Journal of Psychology, 92(2nd Half), 227-234.

Gorawara-Bhat, R., \& Cook, M. A. (2011). Eye contact in patient-centered communication. Patient Education and Counseling, 82(3), 442-447. https://doi.org/10.1016/j.pec.2010.12.002.

Grossmann, T. (2017). The eyes as windows into other minds. Perspectives on Psychological Science, 12(1), 107-121. https://doi.org/10.1177/1745691616654457.

Guillon, Q., Hadjikhani, N., Baduel, S., \& Rogé, B. (2014). Visual social attention in autism spectrum disorder: Insights from eye tracking studies. Neuroscience \& Biobehavioral Reviews, 42, 279-297.

Hadjikhani, N., Johnels, J. Å., Zürcher, N. R., Lassalle, A., Guillon, Q., Hippolyte, L., et al. (2017). Look me in the eyes: Constraining gaze in the eye-region provokes abnormally high subcortical activation in autism. Scientific Reports. https://doi.org/10.1038/s41598-017-03378-5.

Harel, H., Gordon, I., Geva, R., \& Feldman, R. (2011). Gaze behaviors of preterm and full-term infants in nonsocial and social contexts of increasing dynamics: Visual recognition, attention regulation, and gaze synchrony. Infancy, 16(1), 69-90. https://doi.org/10.1111/j.1532-7078.2010.00037.x.

Harris, S. E. (1978). Schizophrenics' mutual glance patterns. Psychiatry: Journal for the Study of Interpersonal Processes, 41(1), 83-91.

Hessels, R. S., Cornelissen, T. H. W., Hooge, I. T. C., \& Kemner, C. (2017). Gaze behavior to faces during dyadic interaction. Canadian Journal of Experimental Psychology-Revue Canadienne De Psychologie Experimentale, 71(3), 226-242. https://doi.org/10.1037/cep0000113.

Hessels, R. S., Holleman, G. A., Cornelissen, T. H. W., Hooge, I. T. C., \& Kemner, C. (2018). Eye contact takes two-autistic and social anxiety traits predict gaze behavior in dyadic interaction. Journal of Experimental Psychopathology, 9(2), jep.062917. https://doi.org/10.5127/jep.062917.

Hessels, R. S., Niehorster, D. C., Nystrom, M., Andersson, R., \& Hooge, I. T. C. (2018). Is the eyemovement field confused about fixations and saccades? A survey among 124 researchers. Royal Society Open Science. https://doi.org/10.1098/rsos.180502.

Hillen, M. A., de Haes, H. C. J. M., van Tienhoven, G., Bijker, N., van Laarhoven, H. W. M., Vermeulen, D. M., et al. (2015). All eyes on the patient: The influence of oncologists' nonverbal communication on breast cancer patients' trust. Breast Cancer Research and Treatment, 153(1), 161-171. https://doi.org/10.1007/s10549-015-3486-0.

Hinchliffe, M. K., Lancashire, M., \& Roberts, F. J. (1971). A study of eye-contact changes in depressed and recovered psychiatric patients. British Journal of Psychiatry, 119(549), 213-215.

Hittelman, J. H., \& Dickes, R. (1979). Sex differences in neonatal eye contact time. Merrill-Palmer Quarterly, 25(3), 171-184.

Honma, M. (2013). Hyper-volume of eye-contact perception and social anxiety traits. Consciousness and Cognition, 22(1), 167-173. https://doi.org/10.1016/j.concog.2012.12.002.

Hore, T. (1976). Visual behavior in teacher-pupil dyads. American Educational Research Journal, 13(4), 267-275. https://doi.org/10.2307/1162389.

Howell, A. N., Zibulsky, D. A., Srivastav, A., \& Weeks, J. W. (2016). Relations among social anxiety, eye contact avoidance, state anxiety, and perception of interaction performance during a live conversation. Cognitive Behaviour Therapy, 45(2), 111-122. https://doi.org/10.1080/16506 073.2015.1111932. 
Hurley, J. R., \& Bennett, M. K. (1988). Interpersonal ratings and mutual eye contact. Small Group Behavior, 19(4), 528-543. https://doi.org/10.1177/104649648801900408.

Hurley, J. R., \& Marsh, V. A. (1986). Contrasting interpersonal correlates of mutual eye-contact reports by self and others. Perceptual and Motor Skills, 63(3), 1267-1274. https://doi.org/10.2466/ pms.1986.63.3.1267.

Iizuka, Y. (1994). Gaze in cooperative and competitive games. Japanese Journal of Experimental Social Psychology, 33(3), 237-242. https://doi.org/10.2130/jjesp.33.237.

Jones, R. M., Southerland, A., Hamo, A., Carberry, C., Bridges, C., Nay, S., et al. (2017). Increased eye contact during conversation compared to play in children with autism. Journal of Autism and Developmental Disorders, 47(3), 607-614. https://doi.org/10.1007/s10803-016-2981-4.

Jundi, S., Vrij, A., Mann, S., Hope, L., Hillman, J., Warmelink, L., et al. (2013). Who should I look at? Eye contact during collective interviewing as a cue to deceit. Psychology Crime \& Law, 19(8), 661-671. https://doi.org/10.1080/1068316x.2013.793332.

Kalma, A. (1992). Gazing in triads: A powerful signal in floor apportionment. British Journal of Social Psychology, 31(1), 21-39. https://doi.org/10.1111/j.2044-8309.1992.tb00953.x.

Keller, H., \& Zach, U. (1993). Developmental consequences of early eye contact behaviour. Acta Paedopsychiatrica, 56(1), 31-36.

Kendon, A., \& Cook, M. (1969). The consistency of gaze patterns in social interaction. British Journal of Psychology, 60(4), 481-494. https://doi.org/10.1111/j.2044-8295.1969.tb01222.x.

Kleinke, C. L. (1986). Gaze and eye contact-A research review. Psychological Bulletin, 100(1), 78-100. https://doi.org/10.1037/0033-2909.100.1.78.

Klusek, J., Ruber, A., \& Roberts, J. E. (2018). Impaired eye contact in the FMR1 premutation is not associated with social anxiety or the broad autism phenotype. Clinical Neuropsychologist, 32(7), 13371352. https://doi.org/10.1080/13854046.2017.1384063.

Knight, D. J., Langmeyer, D., \& Lundgren, D. C. (1973). Eye-contact, distance, and affiliation: The role of observer bias. Sociometry, 36, 390-401.

Krantz, M., George, S. W., \& Hursh, K. (1983). Gaze and mutual gaze of preschool children in conversation. Journal of Psychology, 113(1st Half), 9-15.

Langer, J. K., Lim, M. H., Fernandez, K. C., \& Rodebaugh, T. L. (2017). Social anxiety disorder is associated with reduced eye contact during conversation primed for conflict. Cognitive Therapy and Research, 41(2), 220-229. https://doi.org/10.1007/s10608-016-9813-x.

Langer, J. K., \& Rodebaugh, T. L. (2013). Social anxiety and gaze avoidance: Averting gaze but not anxiety. Cognitive Therapy and Research, 37(6), 1110-1120. https://doi.org/10.1007/s10608-013-9546-z.

Lasalle, L. R., \& Conture, E. G. (1991). Eye contact between young stutteres and their mothers. Journal of Fluency Disorders, 16(4), 173-199. https://doi.org/10.1016/0094-730x(91)90001-s.

Lasky, R. E., \& Klein, R. E. (1979). The reactions of five-month-old infants to eye contact of the mother and of a stranger. Merrill-Palmer Quarterly, 25(3), 163-170.

Leeb, R. T., \& Rejskind, F. G. (2004). Here's looking at you, kid! A longitudinal study of perceived gender differences in mutual gaze behavior in young infants. Sex Roles, 50(1-2), 1-14. https://doi. org/10.1023/B:SERS.0000011068.42663.ce.

Levine, M. H., \& Sutton-Smith, B. (1973). Effects of age, sex, and task on visual behavior during dyadic interaction. Developmental Psychology, 9(3), 400-405. https://doi.org/10.1037/h0034929.

Libby, W. L., Jr., \& Yaklevich, D. (1973). Personality determinants of eye contact and direction of gaze aversion. Journal of Personality \& Social Psychology, 27(2), 197-206.

Lindman, R. (1980). Alcohol and eye contact. Scandinavian Journal of Psychology, 21(3), 201-205. https:// doi.org/10.1111/j.1467-9450.1980.tb00360.x.

Lohaus, A., Keller, H., Lissmann, I., Ball, J., Borke, J., \& Lamm, B. (2006). Eye contact and social contingency experiences from 3 to 6 months of age and their relation to the detection of non-social contingencies. European Journal of Developmental Psychology, 3(4), 388-401. https://doi. org/10.1080/17405620600605323.

Lohaus, A., Keller, H., \& Voelker, S. (2001). Relationships between eye contact, maternal sensitivity, and infant crying. International Journal of Behavioral Development, 25(6), 542-548. https://doi. org/10.1080/01650250042000528.

Lutchmaya, S., Baron-Cohen, S., \& Raggatt, P. (2002). Foetal testosterone and eye contact in 12-monthold human infants. Infant Behavior \& Development, 25(3), 327-335. https://doi.org/10.1016/s0163 $-6383(02) 00094-2$.

MacDonald, K. (2009). Patient-clinician eye contact: Social neuroscience and art of clinical engagement. Postgraduate Medicine, 121(4), 136-144. https://doi.org/10.3810/pgm.2009.07.2039. 
MacLean, P. C., Rynes, K. N., Aragon, C., Caprihan, A., Phillips, J. P., \& Lowe, J. R. (2014). Mother-infant mutual eye gaze supports emotion regulation in infancy during the still-face paradigm. Infant Behavior \& Development, 37(4), 512-522. https://doi.org/10.1016/j.infbeh.2014.06.008.

Mann, S., Ewens, S., Shaw, D., Vrij, A., Leal, S., \& Hillman, J. (2013). Lying eyes: Why liars seek deliberate eye contact. Psychiatry Psychology and Law, 20(3), 452-461. https://doi.org/10.1080/13218 719.2013.791218.

Mann, S., Vrij, A., Leal, S., Granhag, P. A., Warmelink, L., \& Forrester, D. (2012). Windows to the soul? Deliberate eye contact as a cue to deceit. Journal of Nonverbal Behavior, 36(3), 205-215. https://doi. org/10.1007/s10919-012-0132-y.

McAdams, D. P., Jackson, R., \& Kirshnit, C. (1984). Looking, laughing, and smiling in dyads as a function of intimacy motivation and reciprocity. Journal of Personality, 52(3), 261-273. https://doi. org/10.1111/j.1467-6494.1984.tb00881.x.

McCauley, C., Coleman, G., \& de Fusco, P. (1978). Commuters' eye contact with strangers in city and suburban train stations: Evidence of short-term adaptation to interpersonal overload in the city. Environmental Psychology \& Nonverbal Behavior, 2(4), 215-225. https://doi.org/10.1007/BF01173770.

Messer, D. J., \& Vietze, P. M. (1984). Timing and transitions in mother-infant gaze. Infant Behavior \& Development, 7(2), 167-181. https://doi.org/10.1016/S0163-6383\%2884\%2980056-9.

Mobbs, N. (1968). Eye-contact in relation to social introversion/extraversion. British Journal of Social \& Clinical Psychology, 7(4), 305-306. https://doi.org/10.1111/j.2044-8260.1968.tb00574.x.

Muirhead, R. D., \& Goldman, M. (1979). Mutual eye contact as affected by seating position, sex, and age. Journal of Social Psychology, 109(2), 201-206. https://doi.org/10.1080/00224545.1979.9924195.

Nevill, D. (1974). Experimental manipulation of dependency motivation and its effects on eye contact and measures of field dependency. Journal of Personality and Social Psychology, 29(1), 72-79. https:// doi.org/10.1037/h0035727.

Newman, J., \& McCauley, C. (1977). Eye contact with strangers in city, suburb, and small town. Environment and Behavior, 9(4), 547-558. https://doi.org/10.1177/001391657794006.

Niedzwiecka, A., Ramotowska, S., \& Tomalski, P. (2017). Mutual gaze during early mother-infant interactions promotes attention control development. Child Development, 16, 16. https://doi. org/10.1111/cdev.12830.

Nomikou, I., Leonardi, G., Rohlfing, K. J., \& Raczaszek-Leonardi, J. (2016). Constructing interaction: The development of gaze dynamics. Infant and Child Development, 25(3), 277-295. https://doi. org/10.1002/icd.1975.

Nomikou, I., Rohlfing, K. J., \& Szufnarowska, J. (2013). Educating attention recruiting, maintaining, and framing eye contact in early natural mother-infant interactions. Interaction Studies, 14(2), 240-267. https://doi.org/10.1075/is.14.2.05nom.

Orman, E. K. (2010). Effect of virtual reality exposure on eye contact, directional focus, and focus of attention of novice wind band conductors. Journal of Band Research, 46(1), 1-12.

Papagiannopoulou, E. A., Chitty, K. M., Hermens, D. F., Hickie, I. B., \& Lagopoulos, J. (2014). A systematic review and meta-analysis of eye-tracking studies in children with autism spectrum disorders. Social Neuroscience, 9(6), 610-632. https://doi.org/10.1080/17470919.2014.934966.

PelaezNogueras, M., Gewirtz, J. L., Field, T., Cigales, M., Malphurs, J., Clasky, S., et al. (1996). Infants' preference for touch stimulation in face-to-face interactions. Journal of Applied Developmental Psychology, 17(2), 199-213. https://doi.org/10.1016/s0193-3973(96)90025-8.

Pellegrini, R. J., Hicks, R. A., \& Gordon, L. (1970). The effect of an approval-seeking induction on eye-contact in dyads. British Journal of Social \& Clinical Psychology, 9(4), 373-374. https://doi. org/10.1111/j.2044-8260.1970.tb00987.x.

Phillips, W., Baron-Cohen, S., \& Rutter, M. (1992). The role of eye contact in goal detection: Evidence from normal infants and children with autism or mental handicap. Development and Psychopathology, 4(3), 375-383. https://doi.org/10.1017/S0954579400000845.

Pieterse, A. H., van Dulmen, A. M., Beemer, F. A., Bensing, J. M., \& Ausems, M. G. (2007). Cancer genetic counseling: Communication and counselees' post-visit satisfaction, cognitions, anxiety, and needs fulfillment. Journal of Genetic Counseling, 16(1), 85-96. https://doi.org/10.1007/s1089 7-006-9048-1.

Podrouzek, W., \& Furrow, D. (1988). Preschoolers' use of eye contact while speaking: The influence of sex, age, and conversational partner. Journal of Psycholinguistic Research, 17(2), 89-98.

Ponkanen, L. M., \& Hietanen, J. K. (2012). Eye contact with neutral and smiling faces: Effects on autonomic responses and frontal EEG asymmetry. Frontiers in Human Neuroscience, 6, 122.

Rago, W. V., Jr. (1977). Eye gaze and dominance hierarchy in profoundly mentally retarded males. American Journal of Mental Deficiency, 82(2), 145-148. 
Ruggieri, V., Celli, C., \& Crescenzi, A. (1982). Gesturing and self-contact of right and left halves of the body: Relationship with eye-contact. Perceptual \& Motor Skills, 55(3 Pt 1), 695-698.

Russo, N. F. (1975). Eye contact, interpersonal distance, and the equilibrium theory. Journal of Personality and Social Psychology, 31(3), 497-502. https://doi.org/10.1037/h0076476.

Rutter, D., Morley, I. E., \& Graham, J. C. (1972). Visual interaction in a group of introverts and extraverts. European Journal of Social Psychology, 2(4), 371-384. https://doi.org/10.1002/ejsp.24200 20403.

Rutter, D., Stephenson, G., Ayling, K., \& White, P. (1978). The timing of looks in dyadic conversation. British Journal of Social \& Clinical Psychology, 17(1), 17-21. https://doi. org/10.1111/j.2044-8260.1978.tb00890.x.

Rutter, D. R. (1976). Visual interaction in recently admitted and chronic long-stay schizophrenic patients. British Journal of Social \& Clinical Psychology, 15(3), 295-303.

Saenz, J., \& Alexander, G. M. (2013). Digit ratios (2D:4D), postnatal testosterone and eye contact in toddlers. Biological Psychology, 94(1), 106-108. https://doi.org/10.1016/j.biopsycho.2013.05.010.

Schofield, T. J., Parke, R. D., Castaneda, E. K., \& Coltrane, S. (2008). Patterns of gaze between parents and children in European American and Mexican American families. Journal of Nonverbal Behavior, 32(3), 171-186. https://doi.org/10.1007/s10919-008-0049-7.

Schulz, R., \& Barefoot, J. (1974). Non-verbal responses and affiliative conflict theory. British Journal of Social \& Clinical Psychology, 13(3), 237-243. https://doi.org/10.1111/j.2044-8260.1974.tb00116.x.

Schulze, L., Renneberg, B., \& Lobmaier, J. S. (2013). Gaze perception in social anxiety and social anxiety disorder. Frontiers in Human Neuroscience, 7, 872. https://doi.org/10.3389/fnhum.2013.00872.

Senju, A., \& Johnson, M. H. (2009a). The eye contact effect: Mechanisms and development. Trends in Cognitive Sciences, 13(3), 127-134. https://doi.org/10.1016/j.tics.2008.11.009.

Senju, A., \& Johnson, M. H. (2009b). Atypical eye contact in autism: Models, mechanisms and development. Neuroscience \& Biobehavioral Reviews, 33(8), 1204-1214.

Sharpley, C. F., \& Sagris, A. (1995). Does eye contact increase counsellor-client rapport? Counselling Psychology Quarterly, 8(2), 145-155. https://doi.org/10.1080/09515079508256332.

Shaw, M. E., Bowman, J., \& Haemmerlie, F. M. (1971). The validity of measures of eye-contact. Educational and Psychological Measurement, 31(4), 919-925. https://doi.org/10.1177/001316447103100413.

Sitton, S. C., \& Griffin, S. T. (1981). Detection of deception from clients' eye contact patterns. Journal of Counseling Psychology, 28(3), 269-271. https://doi.org/10.1037/0022-0167.28.3.269.

Slane, S., Dragan, W., Crandall, C. J., \& Payne, P. (1980). Stress effects on the nonverbal behavior of repressors and sensitizers. Journal of Psychology, 106(1st Half), 101-109.

Stephenson, G., Rutter, D., \& Dore, S. (1973). Visual interaction and distance. British Journal of Psychology, 64(2), 251-257. https://doi.org/10.1111/j.2044-8295.1973.tb01349.x.

Sturm, V. E., McCarthy, M. E., Yun, I., Madan, A., Yuan, J. W., Holley, S. R., et al. (2011). Mutual gaze in Alzheimer's disease, frontotemporal and semantic dementia couples. Social Cognitive and Affective Neuroscience, 6(3), 359-367. https://doi.org/10.1093/scan/nsq055.

Thepsoonthorn, C., Yokozuka, T., Miura, S., Ogawa, K., \& Miyake, Y. (2016). Prior knowledge facilitates mutual gaze convergence and head nodding synchrony in face-to-face communication. Scientific Reports. https://doi.org/10.1038/srep38261.

Thompson, T. L. (1982). Gaze toward and avoidance of the handicapped: A field experiment. Journal of Nonverbal Behavior, 6(3), 188-196. https://doi.org/10.1007/BF00987067.

Turkstra, L. S. (2005). Looking while listening and speaking: Eye-to-face gaze in adolescents with and without traumatic brain injury. Journal of Speech Language and Hearing Research, 48(6), 1429-1441. https://doi.org/10.1044/1092-4388(2005/099).

van der Geest, J. N., Kemner, C., Verbaten, M. N., \& van Engeland, H. (2002). Gaze behavior of children with pervasive developmental disorder toward human faces: A fixation time study. Journal of Child Psychology and Psychiatry, 43(5), 669-678.

White, J., Hegarty, J., \& Beasley, N. (1970). Eye contact and observer bias: A research note. British Journal of Psychology, 61(2), 271-273.

Williams, J. A., Burns, E. L., \& Harmon, E. A. (2009). Insincere utterances and gaze: Eye contact during sarcastic statements. Perceptual and Motor Skills, 108(2), 565-572. https://doi.org/10.2466/ pms.108.2.565-572.

Yuichi, I. U. (1992). Eye contact in dating couples and unacquainted couples. Perceptual and Motor Skills, $75(2), 457-461$.

Publisher's Note Springer Nature remains neutral with regard to jurisdictional claims in published maps and institutional affiliations. 